\title{
Existing power generation and network facilities improvement against seismic damage
}

\author{
K. Fallahi \\ Sales and Marketing Department, MAPNA Co., Tehran, Iran
}

\begin{abstract}
The optimum utilization of the electricity generated by hydraulic and thermal power plants located in remote and distant areas, which are consequently far from consumption ports, necessitates the establishment of transmission lines and substations. Due to the relative vastness of these regions and special conditions attributed to the ground, the outbreak of various natural disasters, such as earthquakes is highly probable. If an earthquake happens in such areas, the mere interruption in electricity transmission resulting from the partial damage to power utilities is far more destructive than the damage to the power plant itself. In other words, the expenses imposed upon authorities due to the black-outs or brown-outs and the unavailability of infrastructure are considerably higher than the rehabilitation of power plant facilities. Therefore, the execution of power plants in such areas requires a thorough ongoing observation of the behavior and responses of current seismic forces.

Studying the destructive effects of a recent earthquake on the power system (generation, substation, and transmission) in Iran (Bam City, 2004), Philippines and other countries researchers proved the significance of the detailed seismic studies prior to the construction of power system facilities in hazardous areas.

Consequently, for improving the standard utilization of energy, optimizing the current situation, and increasing the safety level for availability of electrical equipment in future projects, it is necessary to deem some procedures to prevent or at least alleviate the destructive effects of earthquakes.

This research concentrates on the study of seismic retrofit methods, and seismic upgrading design for power network facilities based on the foreseen seismic risk assessment of electrical power generation system.
\end{abstract}

Keywords: power generation, seismic, damage, Life line, retrofit, vulnerability. 


\section{Study of earthquake damage}

Study of earthquake damage is an important factor for modifying the design and construction of earthquake resistance systems. In earthquakes, technical and nontechnical installations experience a real test. This will reveal their strengths and weaknesses and would be an appropriate experience for designers.

The damage to power transmission systems due to earthquakes could be divided into two major groups: "direct damage" and "indirect damage."

\section{Direct damage in structural members}

As mentioned before, direct damage is the result of weakness in design and/or construction methods of structural members. This kind of damage can be investigated, considering the type of structural system.

Structural failures are possible in each story and in any kind of structure. They are caused by lateral and torsion displacement, local fracture of supporting members, large displacement of foundations, and collision of adjacent buildings. It is obvious that one of the frequent causes of direct damage in power network systems is the uselessness of facilities in past earthquakes. After earthquakes, although main buildings and installations may not be severely damaged, they are no longer operational and unfortunately, the process of power transmission is inevitably interrupted. Some kinds of such damage are as follows:

- Failure of some of the structural steel members in transmission towers due to damage in foundations

- Settlement or disruption of transmission line foundations and thereby, tilting of towers or extraction of stubs out of concrete

- Collapse of external and internal walls in control buildings, in spite of soundness of structure

- Cable channels disruption and/or tilting of control cabinet supports, which make the tables useless

- Equipment supports disruption in Substations such as rupture of bolts and angles, rotation of foundations and rupture of anchor bolts.

- Collapse of fire walls on transformers

- Settlement and cracking in channels and separation of walls from slabs and/or extraction of cables from walls.

\section{Indirect damage in structural and nonstructural members}

This damage is caused as the result of the destructive effects of other factors and they often make power systems un-operational. Therefore, considering this type of damage is of special importance. In addition, since their causes are not definite, eliminating them completely or preventing their occurrence is not possible in all cases.

These kinds of damage are caused by environmental problems, dissimilarity between equipments' real behavior, and design assumptions and extraordinary conditions, which can be seen in forms of: 
- Soil liquefaction at substations transmission line towers

- Stone downfall from adjacent mountains and cliffs

- Falling of transmission towers due to ground sliding

- Falling and collapse of substations peripheral walls due to ground sliding

- Over turning of power transformers, which are located on distribution poles because of their transformers' weight and inappropriate connections to supports.

- Overturning of batteries in control building due to lack of appropriate supports and position of batteries, which will lead to telecommunication systems and PLC cut-off.

- Damage to the equipment located under gantries (like CVTs, CTs) due to pendulous motions of LTs which are suspended from gantries.

- Horizontal displacement of main and auxiliary transformers and therefore disruption of bushings located on them, which make them useless

- Overturning of transformers from foundations and breaking of bushings and transformers body

- Damage to all porcelain material, insulator, \& bushing due to rigid connection between several equipments together or fall down

\section{Lessons from Bam City earthquake - Iran (2004)}

Iran is a country with several strong ground motions each 50 years, and in each earthquake, many people would die and a lot of buildings, as well as industrial sites - especially lifelines- are damaged.

After the Bam earthquake, some substations and transmission lines were destroyed and when people needed healthcare and transportation facilities, the infrastructures, and lifelines were totally ruined.

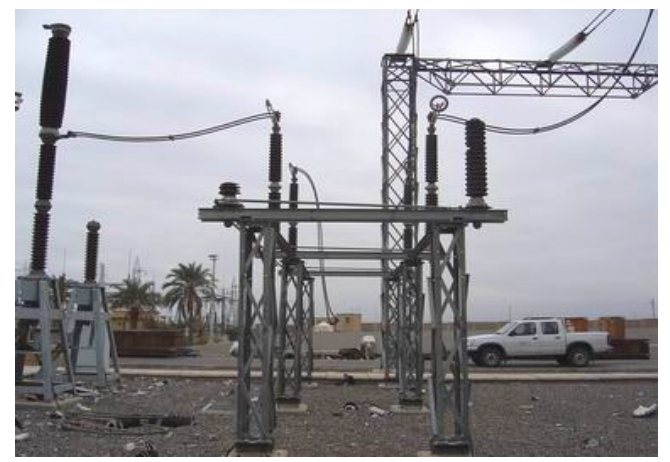

Figure 1: $\quad$ Breaking and collapse "DS" And "CVT".

Many substations in the world and in Iran are constructed by "Turn Key" contracts, so contractors use minimum criteria to consider earthquake force or may not use match code for evaluating seismic loads in order to reduce the costs; therefore, these substations are normally vulnerable. 


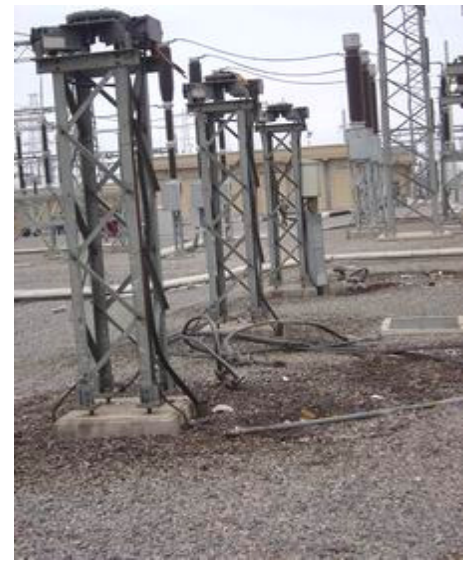

Figure 2: Equipment was broken at connection joint between electrical components and fitting.

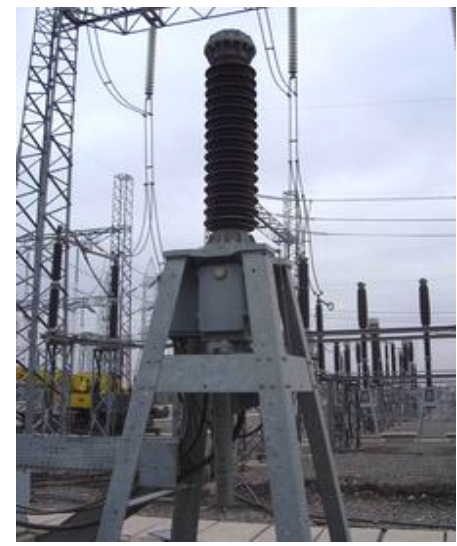

Figure 3: Equipment collapsed at middle longitudinal connection joint due to fitting parts without enough strength capacity against earthquakes and also incorrect embedded shape for porcelain.

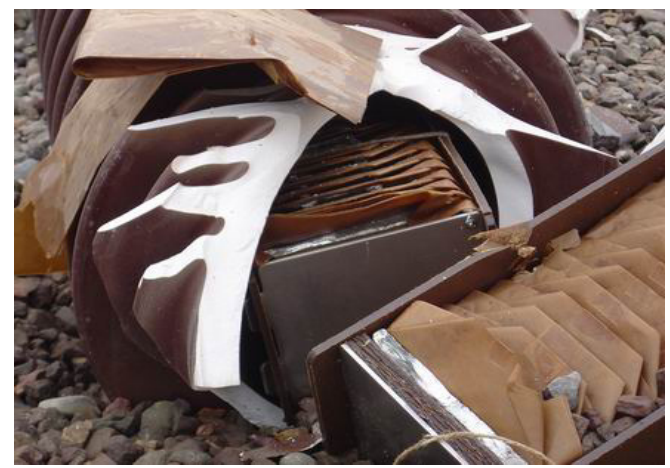

Figure 4: Porcelain part fallen down and electrical internal components damaged.

After the Bam earthquake, about $70 \%$ of urban areas and $90 \%$ of lifelines such as roads, water lines, and electrical facilities were damaged. 


\section{Brief results based on modeling and analysis of some equipment and structure against earthquake loading}

According to a study carried out for evaluation of two substations in Tehran and Tabriz (Iran), the structure and equipment of these two substations, including structural members and non-structural parts, connection accessories, and porcelain were fully modeled with SAP2000 and after loading- based on IEEEStd-693 (84 edition and 97 edition)- with static and dynamic loading methods, the following results were concluded:

- Foundation of the equipment according to depth and dimension due to overturning moments collapsed because depth and foundation weight of these foundation are not enough for resistant moments.

- Bolts for connecting the steel structure to foundation had not enough shear strength for transferring loads to foundation and broke after seismic loads.

- Connection parts, which connect electrical parts to structural supports were not strong enough and damaged due to earthquake loads.

- After the earthquake loads and due to the quality of internal materials, thickness of casing, and joint connection of system to other parts, insulator and electrical portions made of porcelain, could be broken.

\section{Earthquake resistant design}

After assessment of earthquake resistant behavior of structures used in power transmission systems and their predictable damages, a policy should be determined to upgrade unsafe structures in order to be prepared for and keep up against perilous conditions. In other words, the possibility of improving the existing buildings, and optimal design of the structures to prevent severe damage during earthquakes should be determined. There are major solutions:

a- earthquake resistant design during initial design of power systems, b- strengthening of existing structures.

\section{Method of improving earthquake resistance potential}

The first step to reach this goal is to identify the important parameters in improving safety level as follows:

a- Earthquake hazard in the area

b- Economic life of structure

c- Amount and kind of structures vulnerability in case of probable earthquake

d- Architectural requirements

e- Required safety level according to importance and occupancy of structures

f- Time status study

g- Economical aspects

h- Social and political aspects 


\subsection{Steps of studies for selecting appropriate strategy}

a- Earthquake hazarded analysis,

b- Assessment of dynamic characteristic of structures and existing conditions, c- Selection of the best strategy to improve structural system and existing condition, considering the importance of structure and available facilities.

\subsection{Selecting appropriate practical method}

There are generally three practical methods for improving existing condition to prevent structures from damage due to earthquakes:

a- reduction of earthquake demand,

b- Increasing of earthquake resistant structures,

c- Reduction of indirect effects of earthquakes on natural conditions, ground.

Considering the conditions and parameters mentioned above, designers can choose one of the appropriate alternatives. Even for two similar structures located in two different areas with different soil properties and different possibilities to access construction facilities, the ways to improve load bearing capacity and level of safety may be totally different. Since it is not possible to formulate these solutions, each project should be assessed with its own conditions. However, considering the following bases are very useful in selecting the best and most practical methods:

1. Reduction of effective mass by eliminating dispensable weights such as partitions, external walls and heavy claddings weights, weight of structure as the origin of earthquake load will be reduced.

2. Minimizing the distance between center of mass and center of stiffness and therefore reduction of tensional component of earthquake load.

3. Reduction of structures fundamental period: by reduction of mass and increasing the stiffness (appropriately and without considerable increase in earthquake loads). This method is useful for equipment supporting structures which moves through long vibrations and have adverse effect on equipment leaning on them and is possible by adding extra members such as bracings or enlargement of section size.

4. Fastening of lateral load resisting elements to each other in order to increase yielding and strength limit in structures with low level of ductility: since providing high level of ductility is practically difficult, it is possible to reduce demand for ductility by increasing strength.

5. This goal is possible by increasing new members and connecting existing elements to each other reaching. For example, in gantries under heavy loads and transmission line towers, using diagonal braces with reduced laterally supported length increases the strength of the system.

6. Increasing fundamental period and damping of stiff structures, without sufficient strength and ductility subjected to high frequency vibrations: isolators can be used to have appropriate behavior in structures.

7. Increasing stiffness, strength and damping in structures without sufficient ductility or when story drifts or displacements are important. 
In this condition by using pre-stressed bars, EBF and CBF bracings, shear walls and dampers, stiffness and strength of structures will increase and the level of applied loads will decrease and this would lead to a considerable decrease in displacements. This method is generally used for non - laterally resistant control rooms in substations.

8. Isolation of different structures from each other and using cheep filler to prevent direct effect of displacements in some members on other equipment.

9. Use of supporting systems to prevent batteries in switch rooms from overturning: these systems with horizontal and vertical grids prevent the batteries from overturning during reciprocating ground motions in earthquakes.

10. Appropriate fixing of main and auxiliary transformer to their foundations by anchor bolts or rail supports to prevent them from sliding and overturning.

11. Appropriate fixing of distribution line transformers on their respective poles and using sufficient anchors to prevent secondary damage even after overturning.

12. Site grading and clearing the area from damages even after overturning

13. Fixing transmission towers location to prevent piers from sliding motion along slopes.

14. Avoiding from rigid and direct connection between equipment and transformers bushings and changes this connection type to flexible shape.

\subsection{Selecting the best method for retrofitting the design}

In selecting the best method for retrofitting and enhancing lateral load resisting capacity of structures, the whole system including site characteristic, foundations and structural and non structural members should be considered. It is worth mentioning that the evaluation of geotechnical properties, and the type of foundations, is an important stage in selecting the method for retrofitting.

After determining a strategy for improving lateral load resisting capacity of structures, patterns and methods to reach this goal shall be analyzed. The selected final pattern shall consider the technical aspects and costs, and minimize the non conformity between non structural members and their operations. The appropriate method is a method with minimum heavy and professional work and minimum disorder in initial system. In other words, methods which have the most works in external parts of buildings and therefore minimum words, in internal parts are more preferable. In fact the best method is a method that has minimum intervention in operation of buildings.

\section{Design and provide the stable system}

In designing, the invulnerable systems must be used before and after earthquake experience. The behavior of equipment, structures, and buildings due to lateral 
loads can show failure modes, week points, and members after earthquake motion and displacement.

The response of buildings and structures to earthquake ground motion depends on their strength of construction, ductility, and dynamic properties, and reviewing the reports of damaged electrical systems according to past earthquakes is very useful to achieve this goal. Therefore, upgrading existing condition and designing the strength system weekly, requires a sound knowledge about the situation of structural properties, equipment and also the interaction between structural and non-structural components.

Refer to the A.m explanation; new generation of seismic code, recommended to use "seismic performance levels" which these levels defined for stability the structure and condition to continue the maintenances of building.

Many of these codes and also FEMA defined levels:

A) Operational performance

B) Immediate occupancy performance

C) Life safety performance

D) Collapse preventing performance.

On the other hand, cost reducing is one of the most important items in engineering design, designing the building and structures with high resistance and stiffness against the seismic occurrences without considering cost estimate is not economical.

Then new building codes evaluate the structure behavior in three levels:

- Structural and non structural damage prevention due to faintly earth quake which may occur severally in the building life long time. These earthquakes must be sanded in elastic stress limit of materials.

- Supplying enough strength capacity for coping of plastic deformation in secondary members and Structural damage prevention due to moderate earthquakes which may occur several time in the building's life.

- Sustaining high earthquakes that occur rarely without collapsing or structural damaging. In other words, structure must sustain against the most forcible earthquake.

But in using power systems, the above explanation is not applicable, and to obtain a good performance and invulnerable systems, defining compatible performance for electrical system is needed, therefore earthquake codes for substation (like IEEE-Std-693) use 3 levels as:

A) High seismic performance level for high risk earth quake zone:

Equipment that is evaluated by this level, to perform acceptably in ground motion up to the high seismic performance level, without any damage.

B) Moderate seismic performance level for moderate risk earth quake zone:

Equipment that is evaluated by this level, to perform acceptably in ground motion up to the moderate seismic performance level, without any damage.

C) Low seismic performance level for low risk earth quake zone.

These levels are three qualification levels for equipment and their supports, based on seismic hazards according to site condition and also decision of owner. 
A degree of judgment and advanced planning is likely to be involved in selecting performance levels for seismic qualification. The site hazard should not be expected to fall directly on the high, moderate or low seismic performance and a decision to take more risk or less risk will need to be made.

Owners can select the one performance level for their projects according to above subjects, but it must be considered the minimum requirement of earthquake codes for general buildings.

Design process for a resistant module or analyze and retrofitting an existing structure against earthquake force.

Ordinary design and analyze method use from static analyze for calculation of base shear force, stories drifting, plastic deformations which have many foibles. For safety level increasing of an existing structure or designing a new structure it is important to consider following items:

- Calculation of gravitational, wind, electrical force loading and base shear based on static analyze method and structure mass.

- Designing of structure based on upper paragraph result and building codes.

- Determination of reference acceleration earth quake Selection of most forcible probable earthquake

- Determination of structural proper behavior considering to "M.P.E(max probable earthquake", "D.B.E(design basis earthquake)"

- Plastic Dynamic analysis for model of structure and joint strain (drifting), members internal force and plastic deformation.

- Limitation design control, changing member section and try and error repetition step-5 till a confirmed situation on design criteria and balance between strength and ductility.

- Safety level control

- Introducing a part of the requirements in designing of transmission lines, substations and net power systems.

The following items should be considered in the design process by designers:

- Prevention of transmission line passing from the paths which are in land sliding, turnover, cutting, liquefaction hazard area.

- Applying light weight material and mitigation structure mass.

- Using of resisting systems against lateral force.

- Abstention of using brick materials for external walls and use of hallow materials such as hallow clay block.

- Prevention of transmission lines and substations construction where ground property will resonance earth quake force.

- Considering proper development length and a good connection to equipments for insulators during construction time.

- Not to use a direct rigid connection between equipments such as "LT" to "CT" or "CVT".

- Using a proper bracing system for power transformer

- Performing a subtle designing for equipment column, gantries and steel structures against the earth quake force. 
- Produce a proper connection for equipment on structure and foundation with using bolts.

- Performing a proper designing for lightening column in substation yard which may fall on the equipment.

- Performing a proper design for structure component such as fire walls and others which their collapse may affect on equipment.

- Using of ductile bus bars for avoiding striking between equipment.

- Performing a proper design for control building based on real loads and avoiding from increasing the height of building and laying down the weighty loads on high story.

- Performing a proper design for electrical and control cabinet seating.

- Keeping the batteries in the battery rooms and avoiding of falling them.

- Construction a proper barrier around the substations

- Avoiding of construction elevated water tank near equipment.

- Proper connection of distribution net transformers on the pole and beams and bracing their columns.

- Preparing proper bedding for substation equipment and transmission lines foundation from a compacted soil.

- Whereas possibility of occurring short circuit and earthquake at a moment (select this combination, check and control structural and nonstructural members for this combination must be done by owner.

\section{Conclusion}

A comprehensive observation of electrical system response to earthquake or other natural damage shows that the partial or complete damage are mainly due to insufficient strength of electrical parts and foundations, anchor bolts failure, incorrect shape for conductors connecting equipment together and etc. All these factors are reliable guidance for conducting a good "earthquake resistant design for electrical facilities," and thus require studying of the damaged failure mode in previous earthquakes, conducting laboratory tests for electrical equipment and their dynamic behavior, and benefiting from other countries' experience in designing resistant systems.

\section{References}

[1] Fallahi, Kamran, Nateghi Elahi-F., "Disaster Management In Electrical Network And Power Life Line", $3^{\text {rd. }}$ Conference of Quality and Productivity-Tehran- Iran , 2002

[2] NIST -Guide to improved earthquake performance of electrical power system-(NIST-GCR-98-757),1998

[3] IEEE Recommended practice for seismic design of substations (IEEE-Std693), 1997 